\title{
MINKOWSKI LOOP ANTENNA FOR 5G MOBILE COMMUNICATION
}

\author{
Debasish Dash \\ Radio Frequency and Microwave Engineering \\ Electronics and Telecommunication Dept \\ RV College of Engineering \\ Bangaluru, India
}

\author{
Dr. H. V. Kumaraswamy \\ Professor \\ Radio Frequency and Microwave Engineering \\ Electronics and Telecommunication Dept \\ RV College of Engineering \\ Bangaluru, India
}

\author{
Mrunal A Marihal \\ Radio Frequency and Microwave Engineering \\ Electronics and Telecommunication Dept \\ RV College of Engineering \\ Bangaluru, India \\ Dr K.Sreelakshmi \\ Prof \& Head of Department \\ Radio Frequency and Microwave Engineering \\ Electronics and Telecommunication Dept \\ RV College of Engineering \\ Bangaluru, India
}

\begin{abstract}
G or fifth generation of cellular technology, is the successor of 4G LTE. It focusses on high date rate, high system capacity cheaper cost. Although it is still a maturing technology, the countries around the world have already stared implementing of on experimented basis. Massive connectivity is at the core of 5G and thus aim to get different components around us connected to each other. The paper focusses on minkowski loops fractal structures till 2nd iteration making a simpler and cheaper antenna for 5G application of cellular technology. The main feature of this antenna is that it occupied the same space as a regular pattern antenna, but offers a far bigger length for radiation. The resonant frequency taken is 30GHz. The substrate taken is RT-Duriod 6006 with dielectric constant 6.45 . The antenna has been designed, simulated and analyzed using the software high frequency structure simulator.
\end{abstract}

Keywords - 5G, Fractal, massive connectivity, system capacity

\section{INTRODUCTION}

The immense importance to patch antennas is a results of higher demand of compact and cheaper antennas. This leads to a situation where in many scientists and antenna researchers started exploring different ways of harnessing the qualities of patch antennas. A very efficient method of increasing bandwidth and at the same time keeping the size of antenna small is use of fractal antenna. The word fractal means the shapes which always remain same, either zoom in or out. This property gives a very unique capacity of having finite area but infinite perimeter. They are made with a particular iterative algorithm. The most popular fractal structures are Sierpinski gasket, Minkowski loop and Koch loop.

These antennas when formulated to support millimeter waves, which may be used for high data rate which can be used for next generation cellular network.

Today is the age of connectivity and speed. Almost everything in the world is getting connected to one another. The number of things getting connected is increasing exponentially. With the increase in the number of devices \& connectivity it is needed that the speed of connectivity is not compromised.

The review of literatures also confirm of the technologies which can make it happen, on one hand increasing the capacity of the network and on another hand not compromising on speed. It also tells that it is possible to change the characteristics of the antenna without changing the overall height of the antenna [1]. The global bandwidth levels have become very congested because of overuse thus the underutilized millimeter wave's frequency spectrum should be used for future broadband and cellular networks [2]. The 5th generation of cellular mobile data will support various applications like content rich VoIP \& users will be able to connect top multiple applications at once. It will support Ipv6 and flat IP. [3] A very different approach towards achieving the multiband frequencies for the antennas is the use of fractal antennas.

To [4] initiate their investigations into fractal antennas with the aim of designing and antenna which has very low profile and at the same time performing on par with antennas with much bigger size [5]. Designed a fractal antenna which works on $1.8 \mathrm{GHz}$ of frequency. They used famous Koch and Minkowski Loops for the same. They focused on the GPS 
implementation [6]. Used fractal tree patch to achieve multiband applications. The designed antenna with fractal iterations produces a multi band operation for the $\mathrm{S}, \mathrm{C}, \mathrm{X}, \mathrm{Ku}$ and $\mathrm{K}$ bands [7]. Talks of the recent improvements in fractal antenna domain in the design of an antenna for remote applications because of continuously growing importance of remote telecommunication benefits and related applications for voice and information transmission [8].

It designed a fractal tree patch antenna for multiband applications, antenna consists of scaled variations of round patch with a square slot and rectangular connectors[9]. The designed antennas resonate at multiple frequencies with very low return loss and VWSR values [10]. The self-similarity and space filling properties of fractals have been exploited to achieve radiation in $\mathrm{C}, \mathrm{J}$ and $\mathrm{X}$ band regions [11]. It also proposed a new type of square fractal antenna (SFA) structure iterated and optimized by ANN for optimum resonance characteristics covering $1.6-6.6 \mathrm{GHz}$ frequency range. The motivation behind this work is size reduction of MSAs[12].

\section{DESIGN}

In this project an antenna is designed to operate in millimeter wave frequencies. The design is started by taking a rectangular patch as the basic antenna. Since the frequency range selected is extremely high we have to take substrate which gives very less losses[13]. So we took RT/Duroid 6006 According to International Telecommunication Union (ITU) the frequencies from $30 \mathrm{GHz}$ to $300 \mathrm{GHz}$ are millimeter waves, so we took $30 \mathrm{GHz}$

Thus keeping above facts in mind a rectangular patch antenna is designed with substrate of dielectric 6.45 having the thickness of $0.635 \mathrm{~mm}$, radiating patch on top and ground is situated at bottom and designed antenna is simulated using the ANSYS HFSS simulation tool. Microstrip line feed is chosen among the types of feeding techniques, as it will provide impedance matching, and is easy to fabricate and is simple in modelling. The inset feed is the contact feed of microstrip line feed for patch antenna to ensure impedance matching and to reduce input impedance.

\section{A. Equations -}

The dimensions of rectangular patch are calculated by using following equations:

width (W)

$$
W=\frac{c}{2 \mathrm{f}_{\mathrm{r}}} \sqrt{\frac{2}{\epsilon_{\mathrm{r}}+1}}
$$

Effective length $\left(L_{E F F}\right)$ :

$$
L=\frac{C}{2 f_{\text {r. }} \sqrt{\epsilon_{\text {Teff }}}}
$$

Dielectric constant $\left(E_{\text {REFF }}\right)$

$$
\epsilon_{\text {reff }}=\frac{\epsilon_{\gamma}+1}{2}+\frac{\epsilon_{\gamma}-1}{2}+\left[1+12 \frac{h}{w}\right]^{-1 / 2}
$$

Calculation of length extension

$$
\frac{\Delta l}{h}=0.412 \frac{\left(\epsilon_{\text {reff } f 0.8}\right)\left(\frac{w}{h}+0.264\right)}{\left(\epsilon_{\text {reff }}-0.258\right)\left(\frac{w}{h}+0.8\right)}
$$

Length of patch (L)

$$
L=L_{\text {eff }}-2 \Delta L
$$

Substrate length and width

\begin{tabular}{|c|c|}
\hline Parameters & Values \\
\hline $\begin{array}{c}\text { Width of the } \\
\text { patch }\end{array}$ & $2.5906 \mathrm{~mm}$ \\
\hline $\begin{array}{c}\text { Length of the } \\
\text { patch }\end{array}$ & $1.7266 \mathrm{~mm}$ \\
\hline $\begin{array}{l}\text { Width of the } \\
\text { substrate }\end{array}$ & $6.4006 \mathrm{~mm}$ \\
\hline $\begin{array}{l}\text { Length of the } \\
\text { substrate }\end{array}$ & $5.5366 \mathrm{~mm}$ \\
\hline $\begin{array}{l}\text { Thickness/height } \\
\text { of the substrate }\end{array}$ & $0.635 \mathrm{~mm}$ \\
\hline $\begin{array}{l}\begin{array}{l}\text { Width of the } \\
\text { ground }\end{array} \\
\end{array}$ & $6.4006 \mathrm{~mm}$ \\
\hline $\begin{array}{c}\begin{array}{c}\text { Length width of } \\
\text { the ground }\end{array} \\
\end{array}$ & $1.1073 \mathrm{~mm}$ \\
\hline $\begin{array}{l}\text { Width of the feed } \\
\text { line }\end{array}$ & $0.55364 \mathrm{~mm}$ \\
\hline $\begin{array}{l}\text { Length of the } \\
\text { feed line }\end{array}$ & $6.256 \mathrm{~mm}$ \\
\hline
\end{tabular}

$$
\begin{aligned}
& L_{g}=L+6 h \\
& W_{g}=W+6 h
\end{aligned}
$$

Table -1 Dimensions of Proposed Antenna Design

\section{RESULTS AND DISCUSSION}

The proposed antenna design shows the following results using High Frequency Structure Simulator (HFSS) software. In figure $1 \mathrm{a}, 1 \mathrm{~b}$ and $1 \mathrm{c}$ Overlay radiation field is shown where the Overlay radiation field of 2 nd iteration shows good gain results as compared to simple patch and 1st iteration designs. 


\section{A. Overlay Radiation Field -}

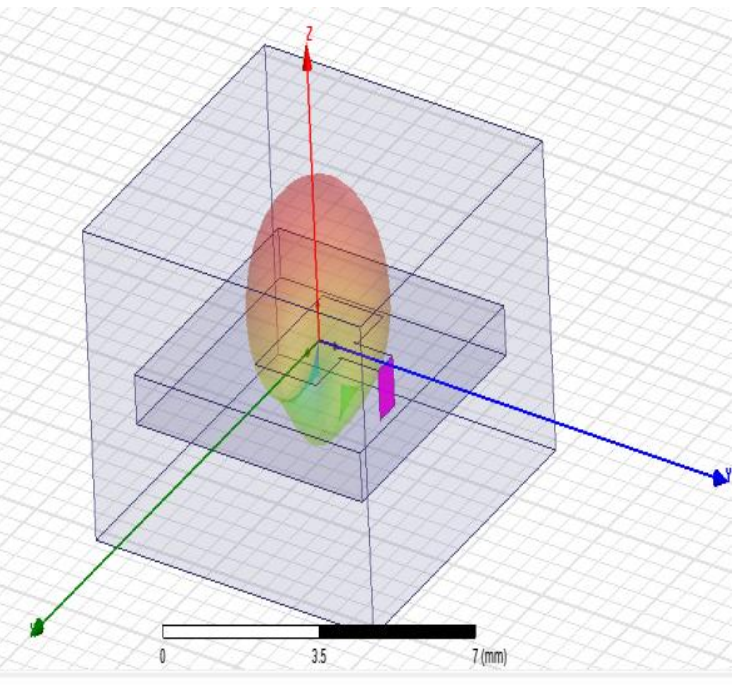

(a)

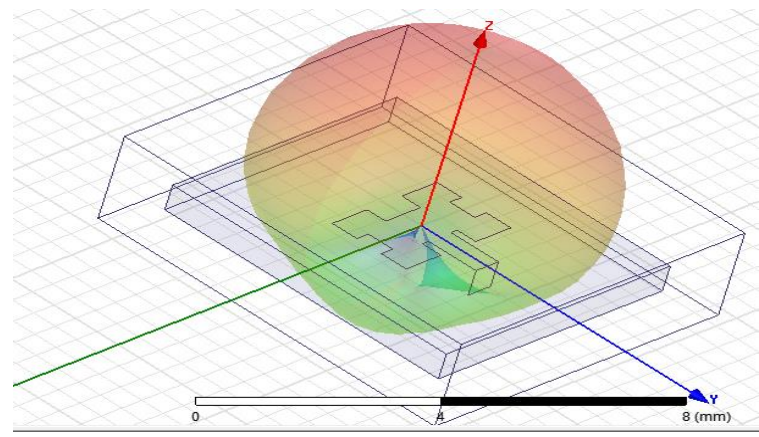

(b)

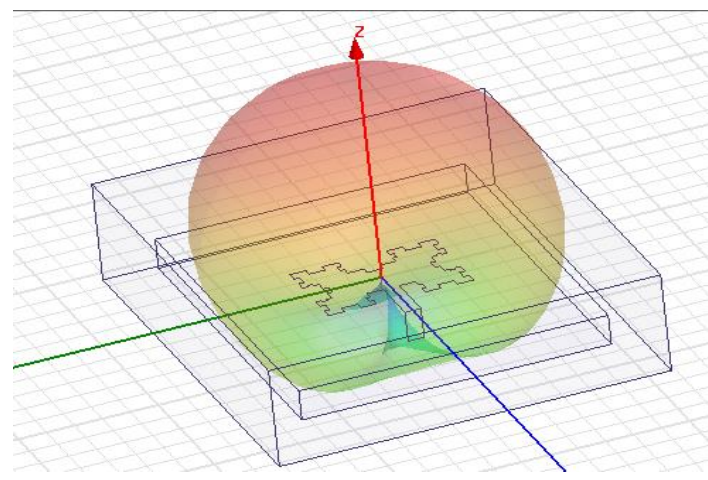

(c)

Fig. 1. (a) Overlay radiation field of simple patch antenna (b) Overlay radiation field 1st iteration (c) Overlay radiation field of 2nd iteration

\section{B. $\mathbf{S}(11)$ (in dB) -}

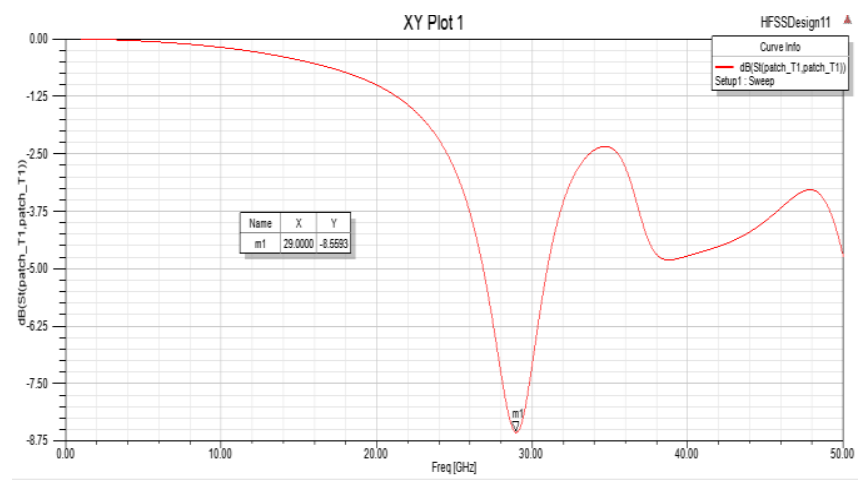

(a)

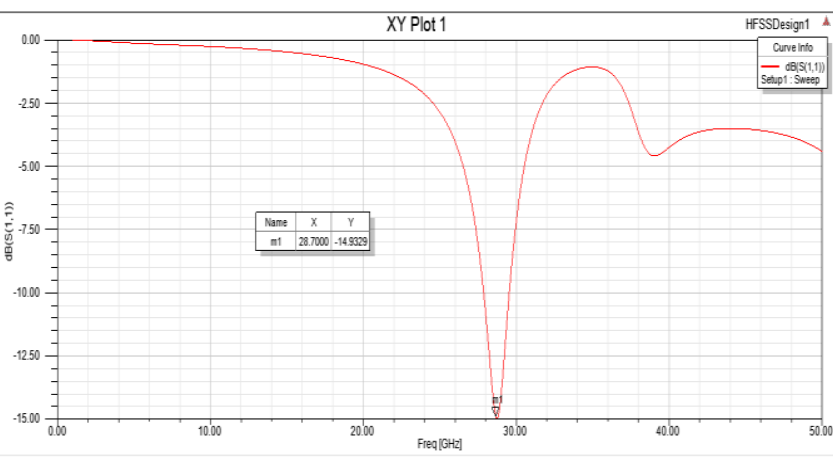

(b)

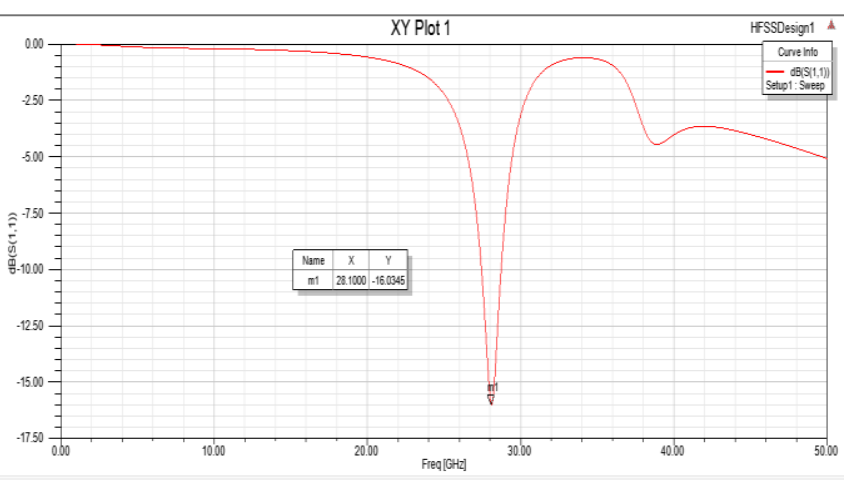

(c)

Fig. 2. (a) $\mathrm{S}(11)$ (in $\mathrm{dB}$ ) of simple patch antenna (b) $\mathrm{S}(11)$ (in $\mathrm{dB}$ ) 1st iteration (c) $\mathrm{S}(11)$ (in $\mathrm{dB}$ ) 2nd iteration

Figure 2 shows return loss. It can be observed that resonance has better return loss there by satisfying the condition S11<$10 \mathrm{~dB}$. Various other parameters of planar antenna like VSWR, Gain pattern and Radiation Efficiency are obtained. It is observed from the figure 3, the Voltage Standing Wave Ratio (VSWR) is obtained in between 1 and 2. 


\section{VSWR -}

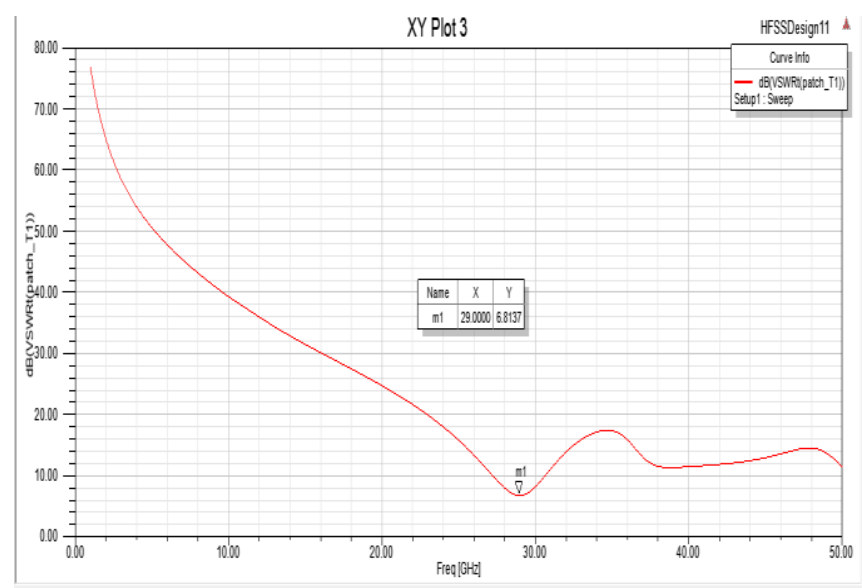

(a)

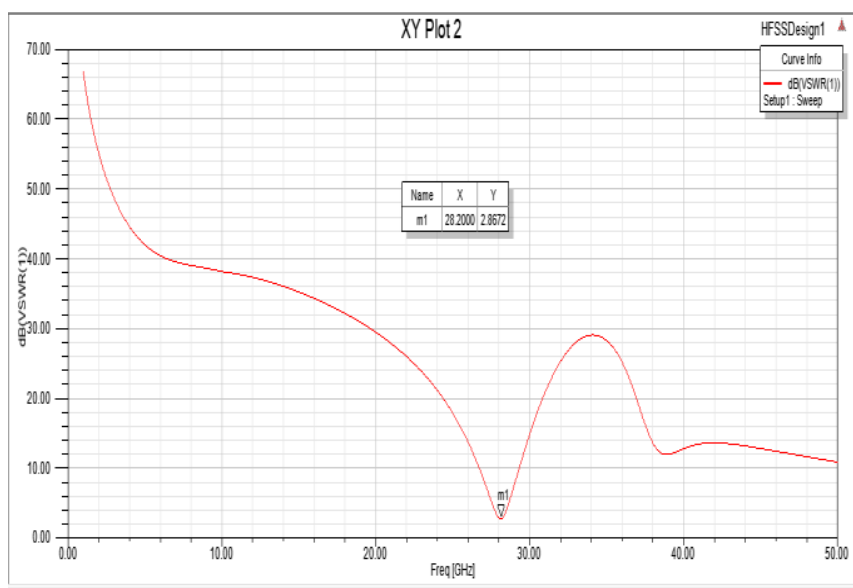

(b)

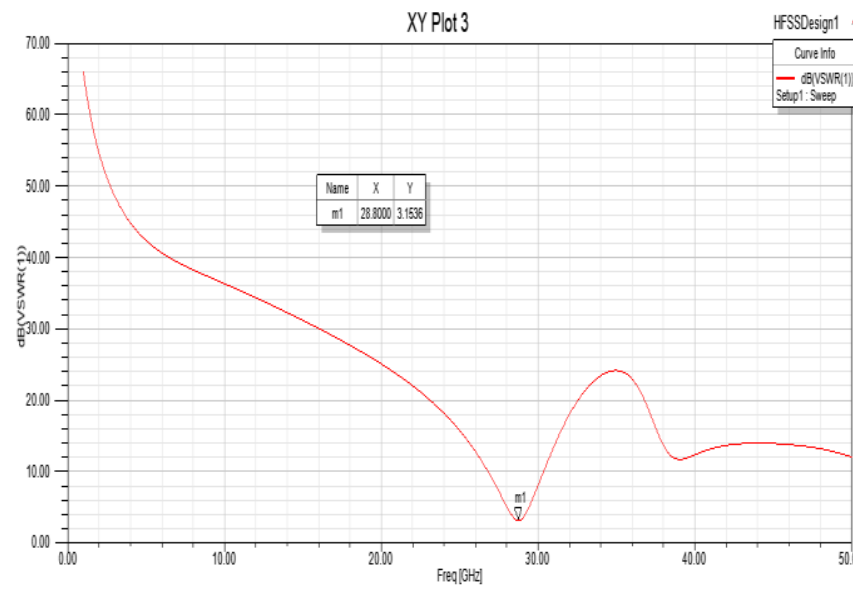

(c)

Fig. 3. (a) VSWR of simple patch antenna (b) VSWR of $1^{\text {st }}$ iteration (c) VSWR of 2nd iteration

\section{Gain Pattern -}
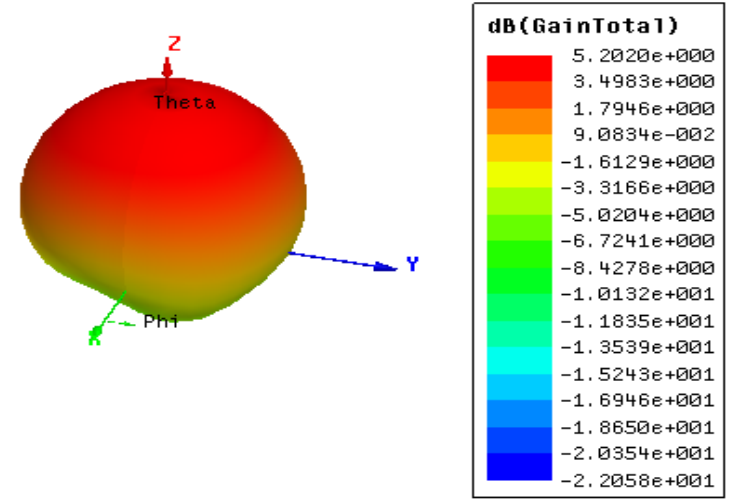

(a)

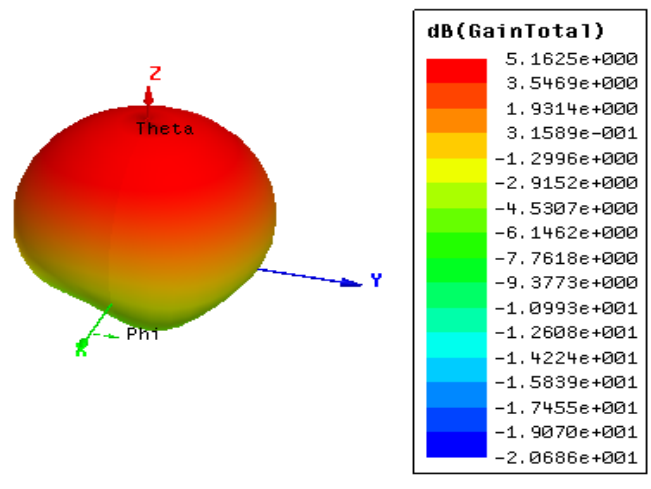

(b)
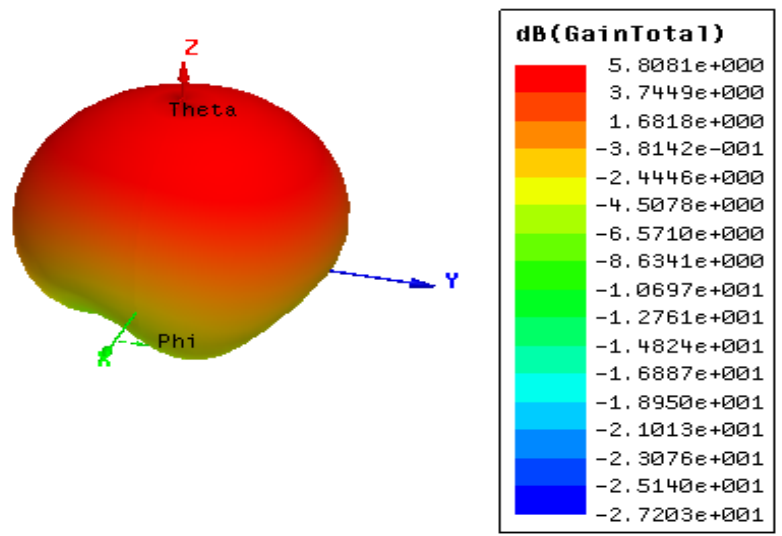

(c)

Fig. 4.(a) Stimulated Gain of simple patch antenna (b) Stimulated Gain of 1st iteration (c) Stimulated Gain of 2nd iteration 


\section{Radiation Pattern -}
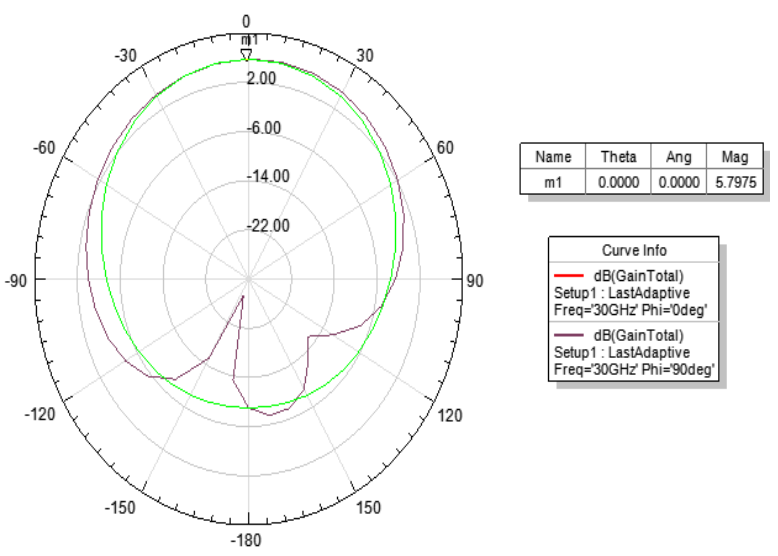

(a)

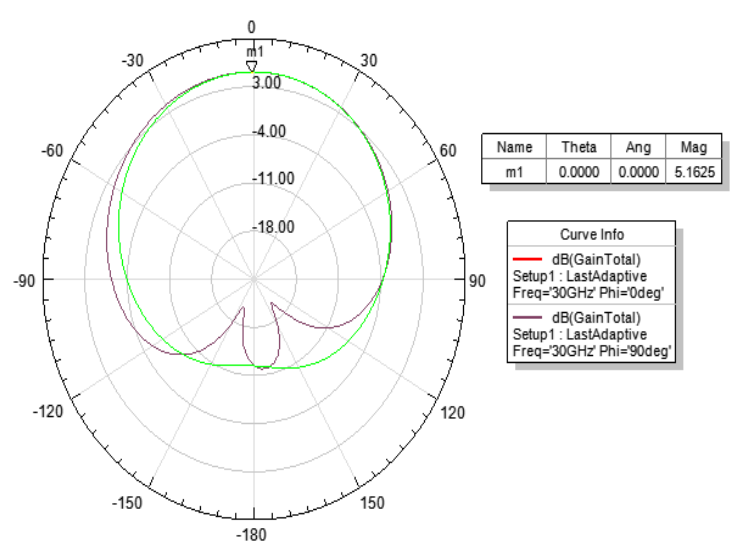

(b)

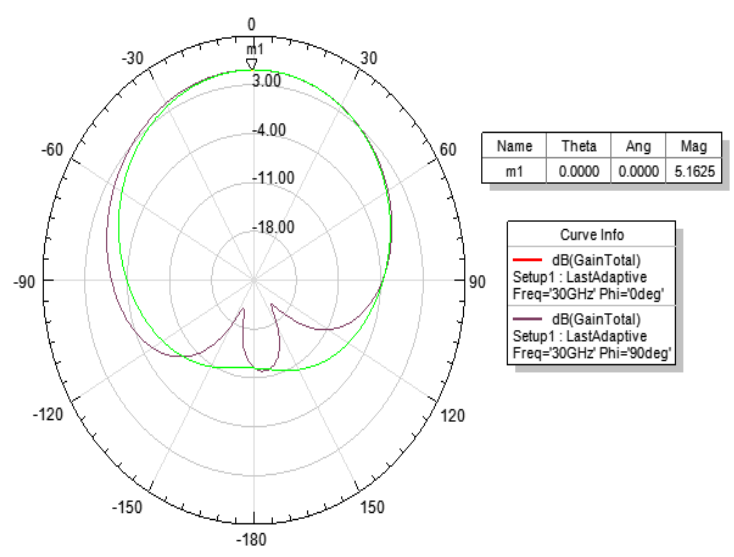

(c)

Fig. 5.(a) Radiation Pattern of simple patch antenna (b) Radiation Pattern of 1st iteration (c) Radiation Pattern of 2nd iteration

Figure 4a, 4b and 4c shows the stimulated Gain pattern for 29 $\mathrm{GHz}, 28.7 \mathrm{GHz}$ and $28.1 \mathrm{GHz}$ respectively. It can be seen from these figures, the Gain of the antenna is as high as 5.2020 / 5.1625 / 5.8081 for $29 \mathrm{GHz}, 28.7 \mathrm{GHz}$ and $28.1 \mathrm{GHz}$ respectively. With the increase in frequency, the gain increases since the adequate area increases. But it does not vary further after a certain frequency since there will be increase in the loss of the substrate and cross polarization.

Figure 5 shows the radiation pattern of the antenna. The obtained magnitudes are 5.7975 / 5.125 / 5.2020 for $29 \mathrm{GHz}$, 28.7 GHz and $28.1 \mathrm{GHz}$ respectively.

Table -2 Experiment Result

\begin{tabular}{|c|c|c|c|}
\hline Antenna Type & Gain & $\begin{array}{c}\text { Return } \\
\text { loss }\end{array}$ & $\begin{array}{c}\text { Radiation } \\
\text { pattern }\end{array}$ \\
\hline $\begin{array}{c}\text { Simple patch } \\
\text { antenna }\end{array}$ & $\mathbf{5 . 2 0 2 0}$ & 29 & $\mathbf{5 . 7 9 7 5}$ \\
\hline $\begin{array}{c}\text { 1st iteration } \\
\text { antenna }\end{array}$ & $\mathbf{5 . 1 6 2 5}$ & 28.7 & $\mathbf{5 . 1 2 5}$ \\
\hline $\begin{array}{c}\text { 2nd iteration } \\
\text { antenna }\end{array}$ & $\mathbf{5 . 8 0 8 1}$ & $\mathbf{2 8 . 1}$ & $\mathbf{5 . 2 0 2 0}$ \\
\hline
\end{tabular}

\section{ACKNOWLEDGMENT}

We would like to thank Dr K Sreelakshmi and Dr. H. V. Kumaraswamy, our mentors and guides who helped us in every step in designing this complex antenna. We would also like to thank RVCE, Electronics and Telecommunication Department for providing us with the tools to design and simulate this antenna.

\section{REFERENCE}

[1] Theodore S. (2013). Millimeter Wave Mobile Communications for 5G Cellular: It Will Work! - NYU Wireless, Polytechnic Institute of New York University, vol.1, (pp. 2169-3536)

[2] Patil G., Wankhade S. (2014). 5G Wireless Technology International Journal of Computer Science and Mobile Computing 2014, Vol.3 Issue.10, (pg. 203-207)

[3] Jena M., Mangaraj B. B., Pathak Rajiv. (2014). A Novel Sierpinski Carpet Fractal Antenna with Improved Performances, American Journal of Electrical and Electronic Engineering, Vol. 2, No. 3, (pp. 62-66)

[4] Gupta V. and Gupta N. (2007). Analysis of a Fractal Microstrip Patch Antenna, International Journal Of Microwave And Optical Technology Vol. 2, No. 2, (pp. 124-129)

[5] Kaloliya V., Koshti M. (2005). Design and Implementation of Fractal Antenna, Nirma University, DOI: 10.13140/RG.2.1.3852.1765

[6] B. Amrutha, I Harikrishnan, (2018). Fractal Tree Patch Antenna for Wireless Applications, International Journal of Advanced Research in Electronics and Communication Engineering (IJARECE) Vol. 7, No. 2, (pp. 114-117)

[7] Adnan S., Asthana P., (2016). Introduction to Fractal Antenna, International Journal Of Innovative Research In Electrical, Electronics, Instruments And Control Engineering Vol. 4, No. 2, DOI: 10.17148/IJIREEICE.2016.4237

[8] Zheng S., Yin Y., Fan J., Yang X., Li B., (2012). Analysis of Miniature Frequency Selective Surfaces Based on 
Fractal Antenna-Filter-Antenna Arrays, in IEEE Antennas and Wireless Propagation Letters, vol. 11, (pp. 240-243), doi: 10.1109/LAWP.2012.2189749

[9] Azari A., (2011). A New Super Wideband Fractal Microstrip Antenna, in IEEE Transactions on Antennas and Propagation, vol. 59, no. 5, (pp. 1724-1727), doi: 10.1109/TÄ.2011.2128294

[10] Khalid T., (2007). Combined Fractal Dipole Wire Antenna, 2007. 2nd International ITG Conference on Antennas, Munich, (pp. 176-180)

[11] Sukaimi N., Ali M., Subahir S., (2013). A multilayer fractal patch antenna using LTCC technology, 2013 IEEE International RF and Microwave Conference (RFM), Penang, (pp. 356-361), doi: 10.1109/RFM.2013.6757284,

[12] Colles D. and Arakaki D., (2014). Multi-technique broadband microstrip patch antenna design, 2014 IEEE Antennas and Propagation Society International Symposium (APSURSt), Memphis, TN, (pp. 1879-1880), doi: 10.1109/APS.2014.6905266

[13] Elsewe M. and Chatterjee D., (2016). Modal analysis of patch slot designs in microstrip patch antennas, 2016 IEEE/ACES International Conference on Wireless Information Technology and Systems (ICWITS) and Applied Computational Electromagnetics (ACES), Honolulu, HI, (pp. 1-2) 